\title{
Warunki technologiczne oraz przykładowe aplikacje regeneracyjnego nakładania powłok metodą brush-plating na powierzchnie metalicznie
}

\author{
Technological conditions and selected applications \\ of regenerative deposition of coatings \\ using brush-plating method on metallic surfaces
}

\section{Streszczenie}

W artykule przedstawiono i scharakteryzowano metodę brush-plating galwanicznego selektywnego nakładania regeneracyjnych powłok metalicznych na części maszyn. Przedstawiono przykładowe rodzaje powłok metalicznych pod kątem ich zastosowania i właściwości. Omówiono możliwości i ograniczenie technologiczne procesu brush-plating.

Słowa kluczowe: powłoki ochronne; powłoki galwaniczne; regeneracja powierzchni

\begin{abstract}
The paper presents and describes the brush-plating method of galvanic selective application of regenerative metallic coatings onto machine parts. Exemplary types of metallic coatings are presented in terms of their application and properties. Technological possibilities and limitations of the brush-plating process are discussed.
\end{abstract}

Keywords: protecting coatings; galvanic coatings; remanutacturing

\section{Wstęp}

W obecnym czasie regeneracja zaawansowanych części maszyn staje się bardzo ważnym elementem w światowej gospodarce. Zasadność i rentowność procesów odtwarzania właściwości użytkowych zaawansowanych części maszyn ciągle rośnie wraz ze wzrostem wartości materiałów inżynierskich, pracy i części maszyn [1]. W wielu przypadkach koszt regeneracji części maszyn po ich naturalnym zużyciu lub po awarii oscyluje na poziomie kilku procent wartości naprawianej części. Znacząco rośnie rola remanufacturingu w przemyśle, a wiele konstrukcji jest zaprojektowanych w sposób ułatwiający w przyszłości ich regenerację [2]. Regeneracja i modyfikacja powierzchni w zależności od oczekiwanych właściwości wytwarzanych powłok i warunków eksploatacji realizowana jest wieloma metodami i z użyciem różnych materiałów powłokowych. Z powodzeniem stosowane są metody natryskiwania cieplnego [3:7], napawania $[8,9]$. Powłoki osadzane są na powierzchniach części maszyn również metodami tarciowymi [10]. Przedstawiono metodę przeżywającą obecnie renesans, opracowaną w połowie ubiegłego wieku, która oparta jest na zjawisku galwanicznego, selektywnego osadzania jonów metali na katodzie z elektrolitu. Najczęściej nazywana jest od angielskich słów jako brush-plating [11].
W artykule przedstawiono przykłady praktycznych zastosowań przemysłowych będące technologicznymi opracowaniami autorów.

\section{Charakterystyka metody brush-plating}

Miejscowa regeneracja metodą tamponowania (brushplating) jest to galwaniczna metoda selektywnego nakładania powłok regeneracyjnych, eksploatacyjnych i dekoracyjnych z miedzi, brązu, mosiądzu, cynku, niklu, chromu, wolframu, wanadu, kadmu, srebra, złota i innych czystych metali, jak również powłok stopowych na metale żelazne oraz nieżelazne. Szeroki zakres zastosowania zawiera także modyfikację i/lub regenerację powierzchni roboczych części maszyn [12], wykonywanie warstw wykorzystywanych w procesach spajania jako warstwy pośrednie [13], czy uzyskiwanie różnorodnych powłok o charakterze dekoracyjnym. Możliwe jest uzyskiwanie powłok jedno, jak i wielowarstwowych o składzie chemicznym odpowiednim do oczekiwanych właściwości takich jak: wysoka twardość, odporność korozyjna, wysoka odporność na zużycie, określona zwilżalność, czy gradient właściwości [14,15]. W ostatnich latach

Inż. Andrzej Radziszewski - RESURS, inż. Adam Radziszewski - Technical Solutions Radziszewski.

Autor korespondencyjny/Corresponding author: andrzej@resurs.pl 
opracowano również warunki osadzania powłok kompozytowych metaliczno-ceramicznych z umocnieniem cząstkami ceramicznymi o nanometrycznych wielkościach [16 $\div 18]$.

Metoda tamponowa w porównaniu z klasyczną metodą galwaniczną charakteryzuje się:

- relatywnie krótkim czasem nakładania powłok (od 10 do 20 razy),

- niskim kosztem procesu wynikającym z tańszego oprzyrządowania i tańszych materiałów dodatkowych oraz niskim zapotrzebowaniem na energię,

- uproszczonymi wymaganiami obsługi stanowiska,

- mobilnością stanowiska, pozwalającą niekiedy wykonać regenerację części bez demontowania ich z maszyny,

- brakiem ograniczeń w rozmiarach pokrywanych powierzchni,

- możliwością manipulowania tamponem (elektrodą) zarówno ręcznie, jak i w sposób mechaniczny,

- możliwością selektywnego pokrywania wybranych obszarów, np. głębokich rys, ubytków, jak odciski śrub na cylindrach w maszynach poligraficznych, czy głębokich rys na tłoczyskach siłowników.

W metodzie tamponowej roztwór elektrolitu doprowadzany jest do pokrywanej powierzchni za pomocą tamponu (szczotki), będącego w kontakcie z elektrodą. Powierzchnia pokrywana charakteryzuje się odmienną biegunowością w stosunku do powłoki pokrywającej. Źródłem prądu jest prostownik o określonej charakterystyce prądowo-napięciowej. Dzięki swojej prostocie, dużej łatwości opanowania techniki nakładania oraz stosunkowo prostemu wyposażeniu podstawowemu stanowiska, metoda umożliwia efektywne i szybkie nakładanie powłok. Istniejąca znaczna ilość elektrolitów pozwala na nakładanie różnych powłok metalowych (w tym stopowych) i kompozytowych, charakteryzujących się szeregiem właściwości, takich jak: odporność na zużycie, wysoka twardość, odporność na korozję, określona zwilżalność oraz lutowność.

Mobilność stosowanych urządzeń dodatkowo podnosi atrakcyjność metody i umożliwia przeprowadzenie nakładania na powierzchnie części maszyn

w miejscu jej pracy. Z kolei stosunkowo łatwe zabezpieczanie (maskowanie) powierzchni elementów przed kontaktem z roztworem elektrolitu, a tym samym osadzaniem powłoki w miejscach niepożądanych, pozwala niejednokrotnie prowadzić proces bez konieczności demontażu elementów maszyny czy urządzenia, co dodatkowo zmniejsza koszty oraz minimalizuje czas przestoju naprawianego urządzenia.

Zakres stosowania metody tamponowej jest szeroki i obejmuje m.in. modyfikację właściwości powierzchni przez nakładanie powłok dekoracyjnych i powłok technicznych. Może być również stosowana $w$ regeneracji powierzchni elementów maszyn i urządzeń (naprawa łożysk ślizgowych, panewek, wałów cylindrów, tłoków, prowadnic, kół zębatych, matryc) uszkodzonych w wyniku pracy lub losowych zdarzeń. Dużą zaletą metody tamponowej jest brak odkształceń termicznych elementów po wykonaniu powłoki.

\section{Nakładanie powłok regeneracyjnych - główne zalecenia}

Proces nakładania powłok metodą tamponową na materiał podłoża w celu modyfikacji lub regeneracji obejmuje bez wyjątków kilka etapów. Pierwszym z nich jest obróbka wstępna powierzchni przeznaczonej do regeneracji, której celem jest przygotowanie powierzchni wyrobu do nakładania powłoki. Można stosować obróbkę mechaniczną, chemiczną lub elektrochemiczną. Obróbka mechaniczna powierzchni powinna zapewnić usunięcie tlenków i innych zanieczyszczeń w warstwie przypowierzchniowej, zaokrąglenie ostrych krawędzi, nadanie powierzchni określonej faktury (np. ozdobnej, co jest często istotne w przypadku powłok o charakterze dekoracyjnym) i chropowatości $[11,12]$.

Nakładana powłoka może być jedno- lub wielowarstwowa. W większości przypadków regeneracji powierzchni wyrobów stosuje się powłoki wielowarstwowe. Najczęściej stosuje się kolejno trzy elektrolity należące do Il. grupy (elektrolity do nakładania powłok). Za pomocą pierwszego z nich nakłada się cienką warstwę podkładową (bond coating), której zadaniem jest zwiększenie przyczepności następnych warstw do materiału podłoża. Następnie odbudowuje się uszkodzoną powierzchnię, nakładając warstwy wypełniające. Stosowanym często $w$ tym celu jest elektrolit umożliwiający nakładanie miedzi. Po odbudowaniu powierzchni nakładana jest warstwa mająca zapewnić wymagane właściwości użytkowe, takie jak np. twardość czy odporność na korozję. Na koniec, jeżeli zachodzi taka konieczność, przeprowadza się obróbkę wykańczającą nałożonej powłoki np. przez polerowanie.

Nie jest możliwe opracowanie uniwersalnej technologii regeneracji powierzchni części maszyn za pomocą metody brush-plating. Wynika to z dużej różnorodności przypadków spotykanych w rzeczywistości. W celu opracowania właściwej technologii osadzania powłoki (metoda obróbki wstępnej, dobór kształtu elektrod i rodzaju elektrolitów, kolejność wykonywania warstw i ich grubość, parametry procesu, obróbka wykańczająca powierzchnię) wymagana jest znajomość wielu czynników technologicznych ściśle ze sobą powiązanych. Przed przystąpieniem do opracowania szczegółowej technologii regeneracji za pomocą metody tamponowej należy określić:

- zadania, jakie ma spełniać powłoka,

- środowisko pracy powłoki,

- przybliżoną trwałość (czas pracy) powłoki,

- sposób działania i "odpowiedzialność" regenerowanej części za właściwe funkcjonowanie maszyny,

- występujące obciążenia działające na powłokę,

- rodzaj materiału podłoża,

- stan powierzchni materiału podłoża,

- kształt regenerowanej powierzchni,

- wielkość i zasięg istniejących uszkodzeń i ewentualnych ubytków materiału podłoża, możliwość demontażu części.

\section{Wybrane przykłady zastosowań}

Poniżej przedstawiono zdjęcia dokumentujące praktyczne przypadki wytwarzania powłok regeneracyjnych na częściach maszyn, opracowanych i wykonanych przez zespół autorów artykułu. Na rysunku 1 pokazano zregenerowany cylinder drukarski po usterce polegającej na zarysowaniu pogrzebaczem. Rysunek 2 dokumentuje proces regeneracji wyerodowanego gniazda osadczego tulei cylindrowych silnika spalinowego. Rysunek 3 obrazuje kolejne etapy regeneracji centralnego otworu korpusu przekładni planetarnej. $\mathrm{Na}$ rysunku 4 przedstawiono przykład regeneracji czopa wału napędzającego śmigło w samolocie Cessna. Rysunek 5 pokazuje zregenerowany wał przekładni zębatej. Rysunek 6 przedstawia korpus ze zregenerowaną powierzchnią uszczelniającą, a na rysunku 7 pokazano efekt prób pokrywania stopu aluminium powłoką srebra. 

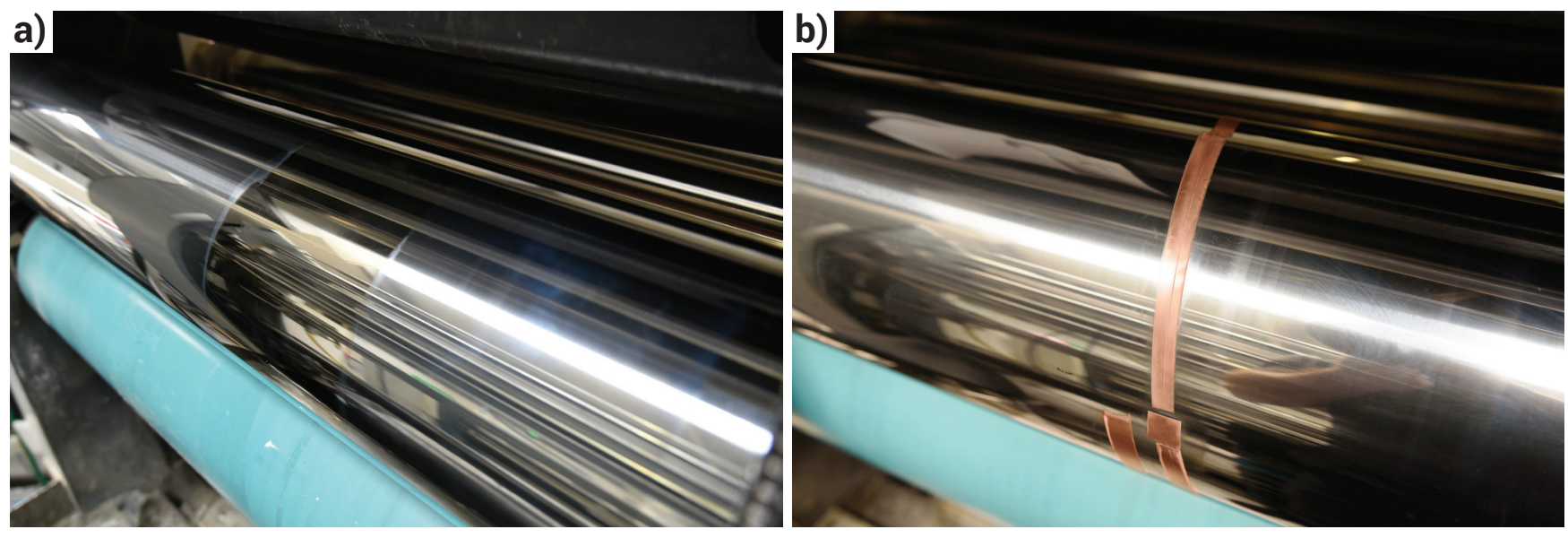

Rys. 1. Naprawa cylindra maszyny drukarskiej: a) podkładowa powłoka miedziana, b) finalna powłoka twardego niklu Fig. 1. Repair of the printing machine cylinder. a) the bond copper coating, b) the final hard nickel coating
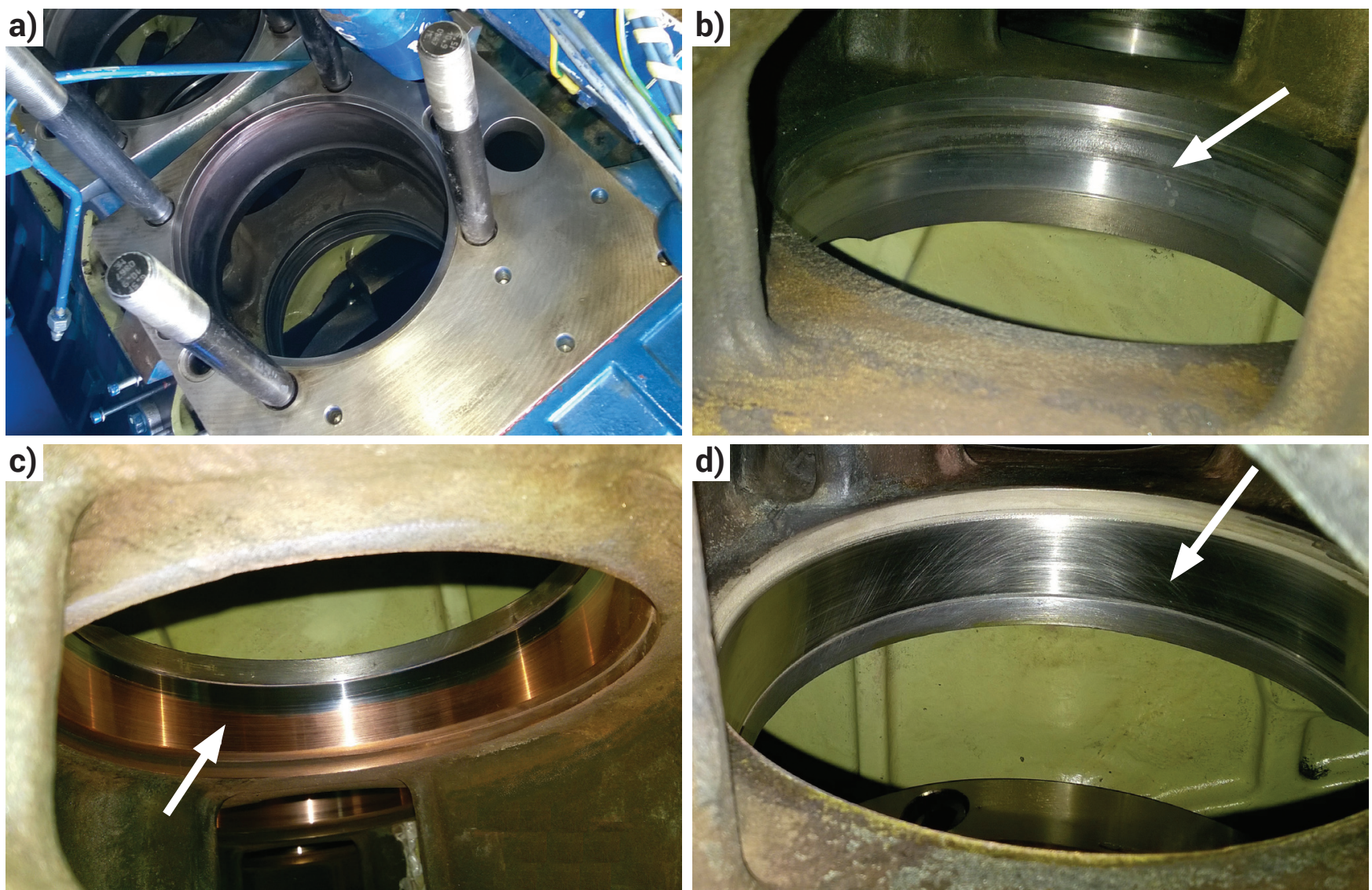

Rys. 2. Regeneracja gniazd osadczych cylindrów silnika spalinowego: a) widok bloku silnika, b) erozja gniazda, c) podkładowa powłoka miedziana, d) twarda powłoka niklowa po obróbce skrawaniem

Fig. 2. Regeneration process of engine cylinder seating sockets: a) engine block view, b) erosion of cylinder seat, c) copper bond coating, d) hard nickel coating after machining

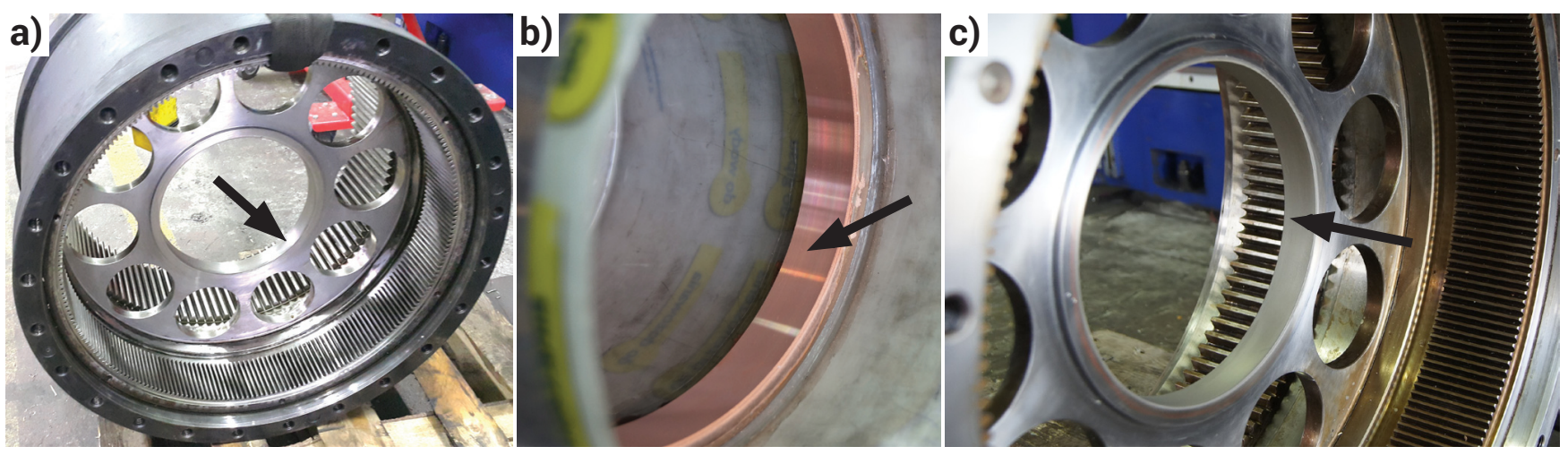

Rys. 3. Obudowa przekładni planetarnej: a) otwór centralnym ø250H8 przeznaczony do regeneracji, b) miedziana powłoka w otworze centralnym, c) powłoka z niklu twardego po obróbce powierzchni

Fig. 3. Body of planetary gear. a) central hole $\varnothing 250 \mathrm{H} 8$ for regeneration, b) copper coating in the central hole, c) hard nickel coating after machining 
a)
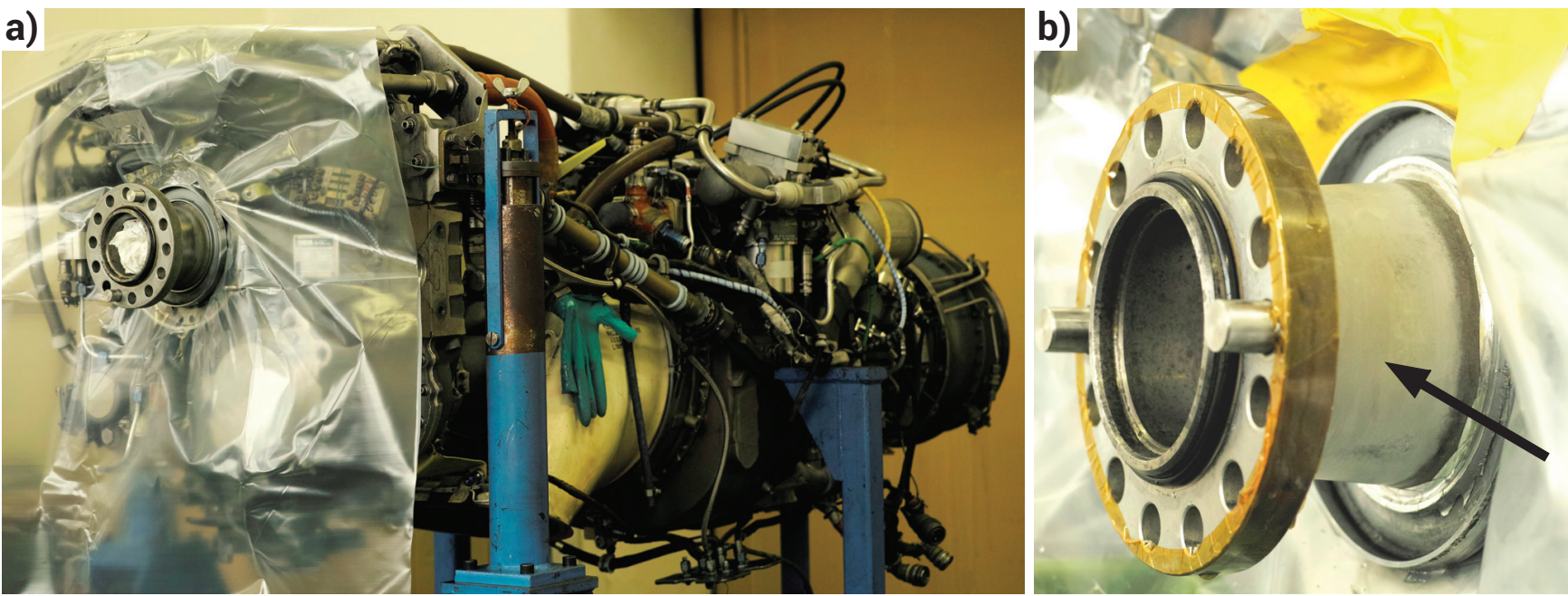

Rys. 4. Naprawa wału napędowego silnika samolotu Cessna: a) widok silnika, b) końcówka wału z naniesioną powłoką Cd Fig. 4. Regeneration of the Cessna Aircraft motor drive shaft: a) engine view, b) the end of the shaft with the Cd coating applied
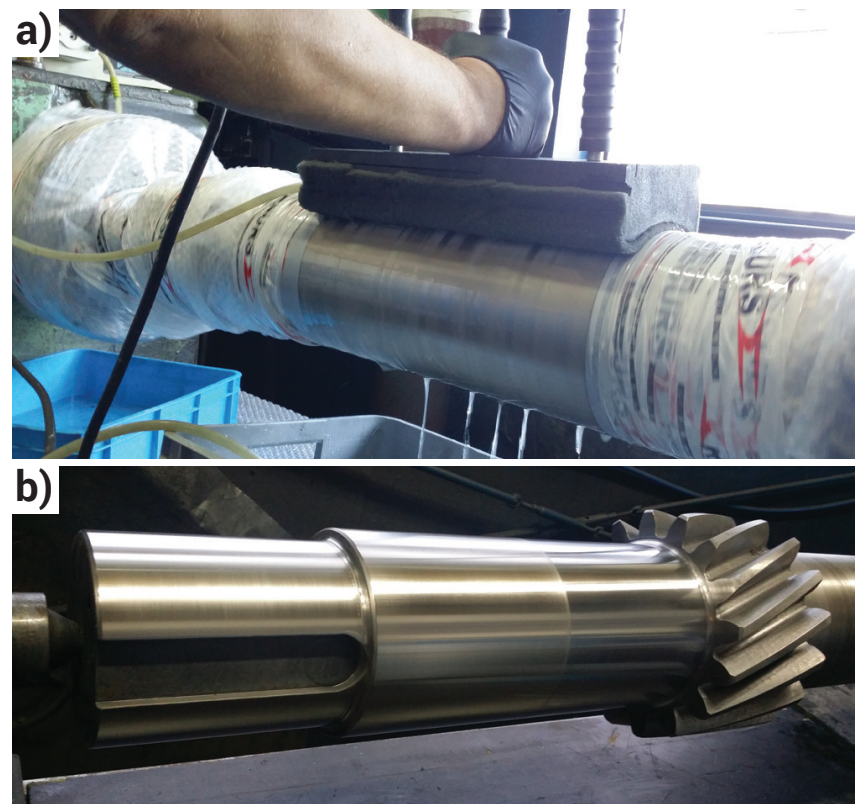

Rys. 5. Regeneracja wału przekładni: a) osadzanie powłoki, b) widok naprawionej powierzchni

Fig. 5. Regeneration of the gear shaft: a) coating deposition, b) view of a repaired surface

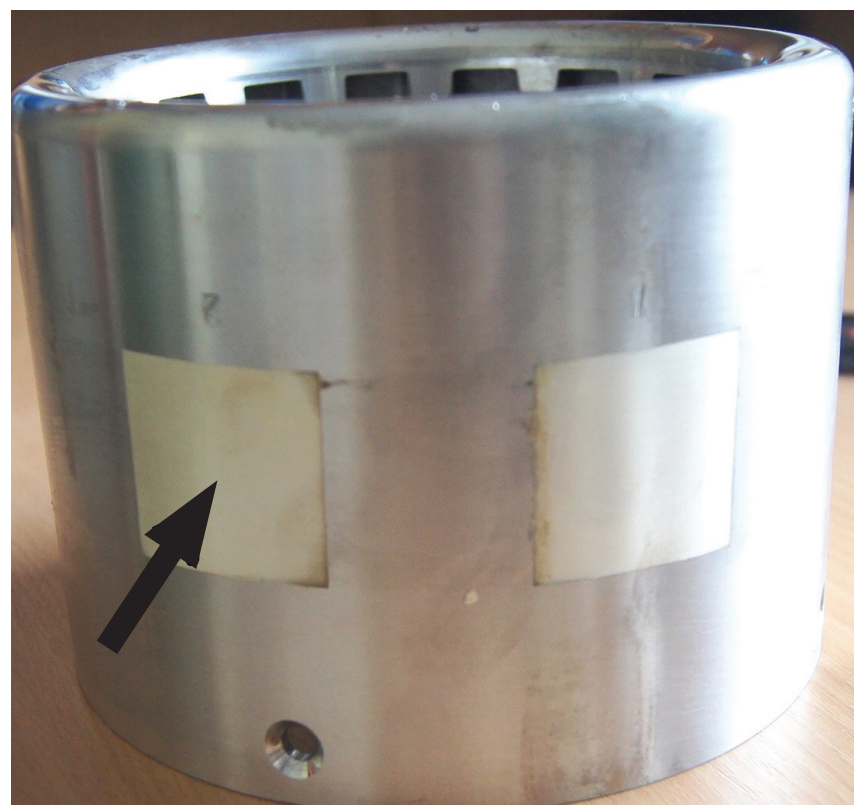

Rys. 7. Tuleja ze stopu aluminium z 2 powłokami srebra o grubości $10 \mu \mathrm{m}$

Fig. 7. Aluminum alloy sleeve with 2 silver coatings, thickness $10 \mu \mathrm{m}$
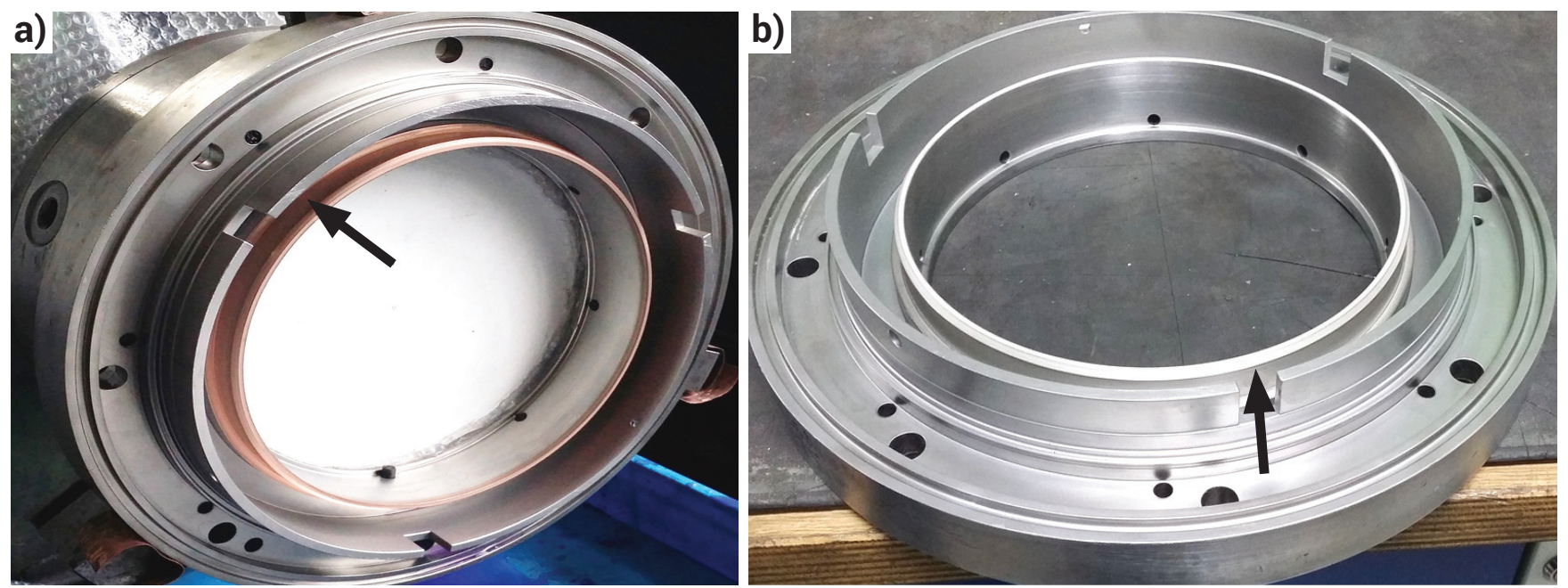

Rys. 6. Korpus uszczelnienia: a) powłoka z miedzi na powierzchni, b) powłoka twardego niklu po obróbce skrawaniem

Fig. 6. Seal housing: a) copper coating on the surface, b) hard nickel coating after machining 


\section{Podsumowanie}

Technologia selektywnego nakładania powłok galwanicznych metodą tamponową (brush-plating) znajduje zastosowanie zarówno na etapie regenerowania części maszyn, jak również może być stosowana w ramach modyfikacji powierzchni w procesie wytwarzania nowych części wykonanych z materiałów przewodzących prąd elektryczny. Opisana technologia umożliwia uzyskanie m.in. powłok: niklowych, nikiel-wolfram, nikiel-wanad i innych, które charakteryzują się stosunkowo wysoką twardością na poziomie 50 $54 \mathrm{HRC}$ dla warstwy właściwej i ok. $48 \mathrm{HRC}$ dla warstwy podkładowej. Grubości powłok mieszczą się w zakresie od kilku do ok. $700 \mu \mathrm{m}$.

\section{Literatura}

[1] Chmielewski T., Golański D.: The role of welding in the remanufacturing process, Welding International, vol. 29 (11), pp. 861-864, 2015

[2] Chmielewski T., Kolasa A.: Spawalnicze metody regeneracji form wtryskowych stosowanych w przetwórstwie tworzyw sztucznych, Spajanie metali i tworzyw w praktyce, vol. 1, s. 25-29, 2010.

[3] Chmielewski T., Jakubowski J.: Żaroodporne powłoki INCONEL 625 natryskiwane termicznie na podłoża ze stali stopowych, Prace Naukowe Politechniki Warszawskiej. Mechanika, vol. 229, s. 143-153, 2009.

[4] Chmielewski T.: Struktura i właściwości kompozytowych powłok ochronnych wykonywanych metodą natryskiwania gazoproszkowego, Kompozyty (COMPOSITES), vol. 3, s. 92-95, 2003.

[5] Niedzielska M., Chmielewski T.: Warunki natryskiwania HVOF powłoki Cr3C2-NiCr na stal 316L, Przegląd Spawalnictwa 89, nr 3, s. 46-50, 2016.

[6] Chmielewski T.: Wykorzystanie energii kinetycznej tarcia i fali detonacyjnej do metalizacji ceramiki, Prace Naukowe Politechniki Warszawskiej. Mechanika 242, 3-157, 2012.

[7] Chmielewski T.: Natryskiwanie detonacyjne metali na podłoża ceramiczne, Przegląd Spawalnictwa, vol. 78, nr 9-10, s. 80-83, 2006.

[8] Chmielewski T., Golański D.: New method of in-situ fabrication of protective coatings based on Fe-Al intermetallic compounds, PROCEEDINGS OF THE INSTITUTION OF MECHANICAL ENGINEERS PART B-JOURNAL OF ENGINEERING, vol. 225 (B4), pp. 611-616, 2011.

[9] Tobota K., Chmielewski T.: Napawanie laserowe powłok ochronnych na powierzchniach roboczych łopatek turbin parowych, Przegląd Spawalnictwa, vol. 88, nr 12, s. 38-42, 2016.

[10] Hudycz M., Winiarski M., Chmielewski T.: Tarciowe metalizowanie ceramiki AIN tytanem, Przegląd Spawalnictwa, vol. 87, nr 10, s. 31-35, 2015.

[11] Grześ J.: Wytwarzanie metodą tamponową metalowych i metalowo-ceramicznych powłok kompozytowych, Kompozyty, nr 5, s. 359-363, 2002.

[12] Grześ J., Rychlewski M.: Metoda tamponowa w regeneracji części maszyn, Przegląd Spawalnictwa, vol. 87, nr 3, s. 30-35, 2015.

[13] Grześ J.: Warstwy pośrednie nakładane metodą tamponową, Przegląd Spawalnictwa, vol. 83, nr 6, s. 48-52, 2011.

[14] Grześ J.: Odporność korozyjna wybranych powłok nakładanych metodą tamponową, Przegląd Spawalnictwa, vol. 86, nr 2, s. 14-18, 2014.

[15] Grześ J.: Możliwości metody tamponowej w zakresie nakładania powłok metalowych z gradientem właściwości, Prace Naukowe-Mechanika, z. 215, WPW, Warszawa 2006.

[16] Dong S.J., Zhou Y., Shi Y.W., Fan L.: A New Hybrid Process for Surface Modification by Combining Brush Plating with Nitrocarburizing, Metallurgical and Materials Transactions A, vol. 33, pp. 2240-2244, 2002.

[17] Wu B., Xu B., Zhang B., Lü Y.: Preparation and properties of Ni/nano-Al2O3composite coatings by automatic brush plating, Surface and Coatings Technology, vol. 201 (16-17), pp. 6933-6939, 2007. DOI: 10.1016/j.surfcoat.2006.12.022

[18] Bin-shi X., Hai-dou W., Shi-yun D., Bin J.: Fretting wear-resistance of Ni-base electro-brush plating coating reinforced by nano-alumina grains, Materials Letters, vol. 60 (5), pp. 710-713, 2006. DOI:10.1016/j.matlet.2005.10.021 